\section{MORGANA DESPIERTA NUESTRA CONCIENCIA}

MORGANA WAKES UP OUR CONSCIOUSNESS

Helena Seoane Pérez Universidad de Oviedo

\section{Resumen:}

Aвstract:

La escritora gallega Begoña Caamaño en su The Galician writer Begoña Caamaño in her libro Morgana en Esmelle analiza el tema de book Morgana en Esmelle analyzes the theme la sororidad, la Real Academia Española, o hermanamiento Real Academia Española, or female twinning femenino o de solidaridad entre mujeres. A or solidarity among women. Through her través deeste personajefemeninotan castigado female character, punished for almost all of the durante casi toda su historia, busca el cambio history, the author seeks the change we should a la hermandad entre hombres y mujeres. men and women. We can find the feeling of Asimismo, planea por la obra un sentimiento guilt in all the characters, so that repentance, de culpabilidad en todos los personajes, de punishment and remorse accompany them tal manera que el arrepentimiento, el castigo during their journey of initiation. The voice y el remordimiento los acompañon durante of the author is simultaneously a pessimistic su viaje de iniciación a cossimistic de la au de iniciacion. Cabe agregar la voz and encouraging voice that Morgana uses to de la autora, una voz pesimista y alentadora point out the social traditionalism anchored simultáneamente, que se sirve de Morgana in some old and obsolete archetypes.

para señalar el costumbrismo social anclado en unos arquetipos antiguos y obsoletos.

\section{KEY WORD:}

\section{Palabras claves:}

Morgana, culpabilidad, sororidad, conciencia.

\section{Morgana Y eSMelle}

Begoña Caamaño era una escritora y periodista gallega que había publicado diversas obras hasta el fatal desenlace de su lucha contra el cáncer. Entre sus obras destacan dos de categoría narrativa: Circe ou o pracer do azul y Morgana en Esmelle. Resulta oportuno mencionar su actividad feminista y su lucha por los derechos de los trabajadores y de los más desfavorecidos. Honrando su memoria y su lucha por la igualdad de la mujer, quiero añadir unas palabras de la escritora en una entrevista que le realizó Montse Dopico: “O entendemento mutuo entre as mulleres, a sororidade, é unha arma de defensa e de empoderamento que só pode facernos máis fortes e máis libres"1.

En Morgana en Esmelle Felipe de Amancia, sirviente de Ginebra, narra la historia de lo que ocurrió en el pueblo con la llegada de su señora y de Merlín, así como la historia previa de cada personaje y hasta dónde va encaminado su destino: el engaño de Uther para conseguir a Igraine, la manipulación de Merlín en la vida de los demás, la disputa entre el mago y Viviana, el final de la enemistad entre Ginebra y Morgana. Del mismo modo, la conciencia de Merlín, cuyo símbolo es la protagonista, expresa el pesar que siente por haber organizado, incluso antes de su nacimiento, la vida de los demás a quienes les ha procurado solamente desgracia e infelicidad. Finalmente, en la voz de Morgana, se expone el sufrimiento que padece cada personaje, la concienciación sobre la carga de culpabilidad que, a causa de sus decisiones, llevarán durante toda su vida.

\section{Culpabilidad}

Tras la lectura de artículos, libros y manuales de diversos temas tales como la filosofía, la historia, la literatura, la psicología (Tejedor Campomanes, César, Historia de la Filosofía en su marco cultural; David Papneau, Filosofía; C.G. Jung, Arquetipos e incosciente colectivo; Ávila Granados, Jesús, La mitología celta; La Vulgata y la Pos-Vulgata de la materia artúrica,etc.), se intenta abordar la culpabilidad, este sentimiento tan complejo al que se accede desde distintos puntos de vista, antes de centrar sus consecuencias en cada uno de los protagonistas principales. De esta manera, se profundiza en las razones por las que han actuado así y por qué este tema recorre las páginas de la obra de la autora.

La culpa ha sido siempre un sentimiento intrínseco a nuestro ser. Principalmente, se puede atribuir al contexto religioso por haber pecado o por llevar una mancha desde nuestro nacimiento, una carga que será expiada dependiendo del grado de arrepentimiento, del castigo que nos imponen o nos imponemos y las acciones que llevamos a cabo para enmendarla.

1 Praza.gal/cultura/791/la-sororidade-e-unha-arma-de-empoderamento-que-so-pode-facernos-mais-libres/ 
En la Antigüedad, los dioses castigaban a los hombres por sus decisiones "libres": Yahvé a Adán y a Eva por la búsqueda de conocimiento; Zeus a Prometeo por robarle el fuego sagrado y ayudar más al ser humano; Dios, porque la humanidad nace ya con el pecado original. Pero, en ocasiones, la libertad de decisión del hombre se coarta por medio de otras vías, no solo religiosas, sino también por la existencia de un control férreo bajo unas estrictas normas jurídicas, sociales y políticas. En el caso de los emperadores y de los reyes a lo largo de la historia han tenido la potestad de aplicar sus penas por mandato divino: Nabucodonosor II con su máxima "Ojo por ojo y diente por diente", las aplicaba con la creencia de ser él mismo el garante del castigo a los hombres. Esto mismo lo ejercían los faraones, los emperadores romanos, los reyes absolutistas, ya que la propia monarquía afirmaba que su institución era constituida por orden divino y respondían solo ante Dios.

En el campo filosófico, el concepto de ética-moral tiene diversas ramificaciones según el filósofo, atendiendo también al sentimiento de culpa, al arrepentimiento y al castigo por un hecho concreto. Aristóteles explica que una acción realizada bajo la ignorancia no puede ser tratada como un acto culpable ya que no existe intencionalidad. Siguiendo el hilo del pensamiento aristotélico, ¿por qué el cristiano debe llevar la carga de una culpa -el pecado original- si realmente no lo ha cometido? ¿Por qué se considera pecado el hecho de que Adán y Eva hayan alcanzado la manzana del Árbol del Bien y del Mal, si ignoraban las consecuencias del acto.

Tal vez, la explicación nos la pueda dar Nietzsche: la crueldad con la que el ser humano lleva ejerciendo sobre el otro ya sea como causante ya sea como recibidor. Dicho axioma está unido a la naturaleza humana: "Ver sufrir produce bienestar; hacer sufrir, más bienestar todavía". Los filósofos cristianos defienden que la religión, concretamente el cristianismo, restaura la paz y elimina cualquier signo de pecado /flaqueza (culpa). Sin embargo, nos encontramos con dos opiniones diversas en Rousseau, quien defiende que la culpabilidad nace por la presión social ya que el hombre nace bueno; en Freud, que habla sobre la conciencia de Culpa por la ausencia de dos bienes: el amor y la satisfacción. Al no expresar sus sentimientos, se subyugan en el inconsciente, creando un sentimiento de culpabilidad, de venganza.

La ética-moral literaria conlleva una deuda que debe resarcirse mediante la reparación del mal causado, aunque signifique la muerte del causador del daño. En muchos textos se nos muestra dicha expiación: Edipo al matar a su padre y al casarse con su madre, el adulterio de Ginebra con Lancelot, etc. Esta desgracia lleva a la ruina tanto al principal causante como a todo lo que le rodea. Arturo se hundió en una profunda depresión y por extensión Camelot, su pueblo y sus tierras. La afrenta será reparada gracias a la búsqueda del Santo Grial y a encontrar la respuesta adecuada: “¿A quién sirve el Grial?” La herida se repara al reconocer su culpabilidad.

Ya se conoce que durante la Edad Media la ética iba unida al concepto de pecado, donde el pecador se separa de los dogmas religiosos, se olvida del dominio de Dios vengador y castigador del Antiguo Testamento. La búsqueda del yo individual aún no estaba "permitida", sino sometida a los designios de un Dios que no le admite ni pensar ni decidir sobre sí mismo. Por lo tanto, la religión asumió los códigos morales como propios viviendo bajo unas rígidas leyes de costumbres y conductas.

No podemos olvidar la posición de la mujer desde el momento que la sociedad se convirtió en patriarcal. Sus normas de conducta aún eran más estrictas que en el hombre, ya que no disponía de moral, añadiendo que procedía del mal y era la causante del pecado original. También se describían como seres inferiores, peligrosas, portadoras de los pecados (vanidad, envidia, pereza, orgullo, lujuria, infidelidad,...), no seguían las normas, se guiaban por la pasión sexual y poseían un lado oscuro diabólico. El culto a la Gran Madre fue desapareciendo poco a poco y cada motivo relacionado con su veneración fue tratado de inmoral y de demoniaco. La dicotomía entre el Bien / Mal, entre Dios / Diablo, queda reflejado en la siguiente explicación sobre la diferencia de sexo: el hombre guiado por el camino de la bondad y la mujer por el de la maldad a través de una vida engañosa, débil, maliciosa como la única culpable del castigo y del dolor que padece el hombre.

En este escenario, la mujer en sí es la culpable de la debilidad del hombre, como descendiente del Diablo, del mal que incita al hombre a pecar. Regía este sentimiento tan fuertemente interiorizado que llegó incluso a la obsesión: la caza de brujas, la Inquisición, la continua campaña de desprestigio hacia las mujeres -ridiculizaban a la mujer hasta el hastío en los textos y, por supuesto, las demonizaban sobre todo aquellas que suponían un ejemplo de lo que no debía ser una mujer cristiana. Por lo tanto, la mujer debía vivir recluida en el hogar; su único objetivo en la vida era cuidar a su familia e hijos y procrear. Si era viuda, soltera o casa y cuida de su aspecto mediante el maquillaje, los accesorios o ropa elegante, eran tachadas de seductoras. Con ello, conseguía aflorar la concupiscencia del hombre y llevarlo al pecado. Mientras que el hombre es el paradigma de buena conducta y es él quien debe seguir los preceptos cristianos. Así lo exime de cualquier responsabilidad porque toda recae en la mujer.

En relación a nuestro personaje principal, Morgana es un claro ejemplo de lo que no está permitido a una mujer. Siempre ha sido considerada una mujer sabia, inteligente, bella, con conocimientos de medicina, de astronomía, dotes para la sanación y para la adivinación desde Geoffrey de Monmouth hasta Chrétien de Troyes. Pero a partir de la tercera parte de la Vulgata empiezan a asomar visos de la decadencia de su imagen que durará hasta la actualidad, como podemos observar en películas tan reconocidas como Excalibur: la enemistad con Ginebra, la constante lucha por acabar con su hermano Arturo, la amante despechada (está enamorada de Lancelot), la desaparición de sus 
características féericas, de adivina para quedar relegada a un plano de transición, a un papel no relevante. Incluso, su conocida belleza y su sensualidad, el hecho de que no había hombre que se le resistiera, sufrió un cambio radical. El hada buena y bella se convirtió en la malvada y fea bruja, estereotipo presente también en nuestros días (el disfraz de bruja). Según sus doctrinas, las cualidades morales eran un fiel reflejo de la p propia imagen, por lo que un ser malvado debía ser imperativamente feo o con taras físicas. A partir del siglo XIII, Morgana será presentada con este nuevo "aspecto". La Iglesia logró acabar con la fama anterior, desvinculándola de toda creencia católica por lo que sería entregada al mal y su guía sería el demonio quien le trasmite sus conocimientos, sus artes curativas, mágicas, etc. Además, su objetivo no solo era borrar vestigios del poder matriarcal en las mujeres de esa época, sino que buscaba también acabar con cualquier religión o herejía diferente que pudiera quitarle la primacía del poder eclesiástico.

Sin embargo, unir la moralidad y la religión nunca ha sido una opción acertada. La religión basa su conducta mediante las creencias o sus propias reglas éticas de la autoridad de un Dios. La moralidad convive con los actos de una sociedad y cómo deben vivir en armonía y en paz. Aunque no se desarrolla bajo una normativa teológica, siempre permanecen resquicios en nuestra la sociedad -por el poder eclesiástico y por otras religiones dogmáticas. ¿Cómo pretenden ambos aliviar el sentimiento de culpa? Esta lleva a la conformidad, a dejarse llevar por una doctrina que acalle los demonios interiores, a no pensar en aquello que se sabe que provoca daño. La religión cristiana y la moralidad imponen normas universales para obrar bien y reparar el fallo que se ha cometido. Todo está dividido entre el bien y el mal, entre recompensa y castigo, entre divino y maligno convirtiendo en sentimiento de odio, de venganza hacia el otro.

Como se ha mencionado anteriormente, la culpa prevalece como sentimiento más plausible junto con la sororidad entre las mujeres. En primer lugar, Merlín se había convertido a la religión cristiana a pesar de ser educado en la tradición pagana y en la isla de Ávalon. Antes de su decisión, se describe al mago con los mismos tintes que vemos en la película antes indicada-Excalibur-, y en los textos medievales: druida, sabio, con dotes mágicas (cambiar de forma) y con una fuerte convicción de ser el detonante de un cambio en la sociedad bretona. Tampoco varía la utilización de Igraine y de Uther para conseguir sus fines: convertir a su hijo en el nuevo rey de todos los pueblos bajo la mirada de la nueva religión. Convence a Arturo a que se una a su causa prometiéndole ser el caudillo de todos los pueblos celtas y ser mejor guerrero que su propio padre, Uther. "Serás non só o rei de todo Britania, senón o gran caudillo que xuntará baixo o seu mando todas as nacións celtas e que dará ao noso pobo un novo rexurdir dentro da nova civilización" (Caamaño, 2012: 54). La rígida moralidad provoca indudablemente el sentimiento de culpa por no haber alcanzado sus metas.
Merlín se había impuesto un reino gobernado por un único soberano y por una única religión. Al principio, compartió su sueño con Viviana, pero cada uno creía en una idea de bondad y de justicia. La druida Viviana pensaba en salvar la sabiduría y el conocimiento albergado en la isla; al contrario, Merlín abrazó la religión cristiana -ya expandida en toda Europa- como la salvación a un pueblo anclado en sus antiguos ritos que los llevaría a la absoluta desaparición. Critica la actitud de los druidas frente al mundo y explica su declive a partir de la llegada de los romanos. Dicha diferencia obligó a Merlín a abandonar la isla. A raíz de este momento, su culpabilidad se percibe mejor porque no siente el apoyo que creía haber encontrado en una persona tan especial como Viviana quien mantenía a raya su lado oscuro y su dualismo (engendrado por una mortal y un demonio).

Asimismo, se muestra un personaje atormentado que ha tenido que enfrentarse al ataque de los demás por poseer una genealogía oscura. La culpa que se compagina con la angustia, la ansiedad y el remordimiento provocó un cambio en la actitud del mago, esto es, se volvió más ambicioso y creía que su misión era salvar a su pueblo celta. Elige a Arturo como el futuro rey de los celtas, a Ginebra como su mujer por haberse educado en la religión católica y así poder extender el cristianismo en Britania. “O momento en que Artur, xa rei indiscutido de toda Britania, por fin caudillo de todas as hostes celtas...e públicamente a fe cristiá" (Caamaño, 2012: 148).

“Comenzou aí a miña primeira gran culpa, pois fun eu, tanto como ela, responábel de convencer a asemblea de druídas de que era o único detino posíbel para a nossa terra amada" (Caamaño, 2012:167). Aquí podemos unir el sentimiento de culpa en los dos personajes. Ambos buscaban el bien del pueblo celta, pero de diversa manera: Merlín, un pueblo gobernado por un solo caudillo y por una sola religión a la par de un César y del imperio romano; Viviana, quería que Bretaña fuera una república porque así los hombres y las mujeres eran libres por igual y, por supuesto, sin una religión dominante que impidiera la libertad del pueblo. Sin embargo, ninguna de las dos vertientes triunfó ya que su ambición personal obstaculizó el bienestar popular y desató unas consecuencias imprevisibles en los demás: la infelicidad.

Todo el texto es un canto a la petición de perdón de Merlín porque en la mayoría de los capítulos es su conciencia la que habla constatando en cada uno cómo ha cambiado su destino. Por ejemplo, en el capítulo Da conciencia do señor Merlín, Xenebra, el mago se arrepiente de haber planeado el destino tanto de Ginebra como de Arturo ya que solo les había causado desgracias. Además, tampoco culminó su fin de que solo reinara un rey y los demás pueblos estuvieran a sus órdenes. Su soberbia y su ambición trajeron la tristeza y el deshonor de buenas personas. "Esta muller que me reclama está no seu dereito de me atormentar. Eu traizoeina. Traizoeina como fixen coa súa nai, Igraine. Com fixen con Viviana. Como fixen ata coa pobre Xenebra" (Caamaño, 2012:193). 
Merlín arrepentido, opta por cargar con su culpa y decide llevar a Ginebra a Esmelle para que fuera al menos la dueña del lugar y allí podrían olvidarse de todo y rehacer su vida. En el transcurso de la obra vemos la evolución del personaje desde un principio que, aunque se mostraba dubitativo, temeroso de su pasado, se sentía seguro de lo que debía hacer para cambiar la situación en la que se encontraba el pueblo. Intervino en la vida de Arturo, de Ginebra y de sus padres, sin ningún tipo de conciencia, solo con la motivación de cambiar su destino. "Igual que Artur, Xenebra foi pensada por min antes de ela nacer. Fun eu quen se fixou no rie cristián Leodegrance e quen decidiu que unha súa filla sería a esposa necesaria para Artur" (Caamaño, 2012: 194).

El siguiente personaje a tratar como contrapunto a los deseos de Merlín es Viviana. Al igual que Morgana es descrita como descendiente de hadas, con poderes de adivinación y visionaria. Ambas pertenecían a la familia de Igraine: Morgana, su hija y Viviana era su hermana mayor. Gracias al respeto que la religión celta mostraba a las mujeres y al culto que siempre ha prevalecido a la Gran Madre, las características propias son positivas, por ejemplo, era una gran maestra, una druida y una sabia a la que pedían asesoramiento también sus compañeros del consejo. Los druidas, con Viviana a la cabeza, deciden "vengar" el engaño que hizo Merlín a Igraine y a Uther para que concedieran a Arturo. Este propósito será junto con la protección de la isla de Ávalon lo que llevará a la druida a un sentimiento de frustración por no poder ejecutarlo. Tanto Viviana como Merlín utilizan a Arturo para sus propios fines ya que para ellos representa la esperanza de la continuidad de las tradiciones celtas y de la implantación de la nueva religión respectivamente. Se lo disputan como si estuvieran jugando al ajedrez y cada movimiento supone un paso para su triunfo. Ambos manifiestan tal soberbia y falta de empatía hacia los demás, que prácticamente la autora ejerce una justicia poética al no concederles la satisfacción de ganar.

Merlín se recluye en un pueblo y cambia, arrepentido, de forma de actuar. Sigue siendo un druida sabio, pero sus actos y sus pensamientos son humildes. Igualmente ocurre con Viviana, pero en este caso, se recluye en la isla, considerada un recodo sagrado y mágico independiente del mundo real. Es el único lugar donde se siente apartada de las vanidades humanas, de la influencia de una sociedad patriarcal, de un mundo regido por una religión que subyuga al hombre, que crea desigualdad y que restringe la libertad del ser humano. “Manter a humanidade submisa, pregada aos mandados dun ser superior que ninguén ve e que ninguén coñece...o medo para impoñer as normas que máis lels conveñen?" (Caamaño, 2012:104).

Sus desavenencias se demuestran también cuando hablan de la siguiente afirmación aristotélica "O fin último é a felicidade" (Caamaño, 2012:108): Merlín creía que a través del cristianismo se garantizaban los suministros básicos; por el contrario, Viviana no aceptaba que los bienes materiales estuvieran por encima de la libertad personal.
Tal vez la protagonista más atormentada de la obra sea Ginebra a razón de su rígida educación católica en un convento (antes de vivir en Esmelle se recluye de nuevo en uno para expiar su pecado) y de su posterior misión maquinada por Merlín para que se convirtiera en la esposa fiel de Arturo. Simboliza todo aquello que el cristianismo pregona: una mujer sumisa, enclaustrada en una casa, desempeñando solo las tareas destinadas a mujeres (tejer, ser una esposa virtuosa, educada en los cánones cristianos). Dedica su vida a un hombre que no conoce (Arturo), su matrimonio está concertado desde la niñez, pero realmente está enamorada de otro, el caballero triste -Lancelot. Morgana y Merlín conocían este amor. Sin embargo, en la obra no hay ningún tipo de relación adúltera, como podemos encontrar en los textos clásicos de la materia artúrica (Lancelot, el caballero de la carreta; La búsqueda del Santo Grial), solo el amor que profesa al caballero. Esto conlleva que el pecado cometido sea de pensamiento y no de obra. Pero basta para condenarle a padecer una angustia al no aportar la felicidad a su marido ni al darle un hijo que sería el verdadero rey de los britanos. El castigo que se impone será romper con Arturo y todo lo relacionado con Camelot y confinarse en un convento hasta que la libera Merlín.

En relación a Arturo, su papel es un hilo de conexión entre los deseos de Merlín y los de Viviana, asimismo la llegada de las desgracias de todos. La relación incestuosa que mantiene con su hermana Morgana provoca el estadillo de los sentimientos ocultos y el fin de los planes del mago con respecto al pueblo celta. Arturo decide llevar su culpa a través de unos inflexibles códigos religiosos y rechaza aquello que le recuerde a su hermana, esto es, la tradición pagana y la libertad de pensamiento.

Por último, Morgana es el modelo opuesto a Ginebra en la mayoría de los textos y, en el que nos ocupa también. Al nacer en un ambiente pagano, libre e igualitario para las mujeres, ella misma decide su destino: ir junto a su tía Viviana a vivir durante unos años en la isla de Ávalon para aprender todos los conocimientos que allí se amparaban. Ya conocemos que Ginebra no era libre para elegir su propia vida, sino que, desde antes de su nacimiento, el matrimonio con el rey céltico ya estaba impuesto. Toda su trayectoria se dedicaría a cumplir el papel de esposa perfecta cristiana. Antes de su partida, tuvo que ocuparse de su hermano Arturo debido a que su madre Igraine cae en una profunda depresión cuando se entera de que Uther es el verdadero padre de su hijo y de la traición por parte de Merlín. El cuidado de su hermano es un hecho muy importante ya que la felicidad que sienten los dos hermanos será una de las causas de remordimiento en Morgana en el momento que Arturo determina seguir al mago en sus pretensiones y romper con su vida anterior. Otro punto a tener en cuenta es la descripción mayormente positiva de su personaje: la autora, salvo en escasas ocasiones y en boca de algún personaje por el miedo que despertaba su poder, la describe como una mujer sabia, inteligente, respetada en las asambleas, dedicada al estudio (en la 
isla) y ya con poder adivinatorio. "A nena Morgana foi aquela mañá a primeira en saber da chegada do novo señor [...] a mesma sombre de dragón que vira o día da morte do pai” (Caamaño, 2012: 23); “Na comunidade druídica achou a nena a vida que desecaba [...] destacou pola súa inteligencia e sagacidade e polo seu amor e dedicación ao estudo" (Caamaño, 2012:115)

Cuando Morgana regresa a Camelot para asistir a la boda de Arturo y de Ginebra, vuelven los recuerdos de una infancia plena. Sabe que su hermano no es feliz porque está viviendo el sueño de otra persona, Merlín, porque se había guiado por los vicios de ambición y poder y, porque era conocedor del amor entre Ginebra y el caballero de los ojos melancólicos. “Morgana sabía que tamén Artur era coñecedor desa paixón vedada que con tanta forza atría dous dos seres que el máis estimaba" (Caamaño, 2012:172)

Se usa el leitmotiv presente ya desde la aparición de su personaje en Historia de los reyes de Britania de ser la cuidadora de las heridas de Arturo, pero no para sanar las heridas físicas de un rey, sino las del alma a causa de su desdicha. Pretendía devolverle la ilusión de vivir, llevando hasta el extremo el amor puro hacia su hermano, esto es, yacen juntos. El incesto provoca un giro de $180^{\circ}$ y el final de las pretensiones de todos ellos. Al enterarse, el pueblo, creyendo desde un principio las malas artes del hada, ordena expulsarla por haber embrujado al rey para que cometiera dicha traición. Por lo que Arturo, lleno de angustia y de arrepentimiento, se encierra en las más estrictas normas católicas para expiar su falta. "pola súa abominación caese sobre Britania iniciou a busca do cáliz onde, segundo a nova relixión, se vertera o sangue do agora considerado como fillo do Deus único" (Caamaño, 2012:179).

Morgana queda embarazada de la última esperanza de la tradición pagana: su hijo, Mordred, quien será el causante de la muerte de su padre. Durante un cierto tiempo, no se arrepiente de este hecho, más bien, surge un sentimiento de odio hacia aquellas personas que estaban en desacuerdo con su relación y, más concretamente, hacia su hermano porque no ha sido lo suficientemente valiente de aceptar el amor entre ambos y luchar contra los prejuicios morales fuertemente arraigados en la sociedad y, por supuesto, hacia Merlín como causante primero de la desgracia general. Sin embargo, acaba reconociendo el error que había cometido al intentar "salvar" lo que ella creía que era un mundo dichoso junto a Arturo.

Su cambio se debe a diversos motivos: en primer lugar, a la actitud que encontró en Merlín una vez que visita Esmelle. Ya no era ese hombre soberbio, guiado por sus ambiciones, más bien, se había convertido en un ser humilde e interesado en ayudar realmente a los demás. En segundo lugar, su propio remordimiento, su amor habían originado el fin de un ciclo y de un mundo irreal, ficticio. En tercer lugar, su confesión de haber "pecado" de soberbia al igual que aquellas personas que había detestado por actuar así -Viviana y Merlín. “En Miranda tamén me atrapou a min o castigo. [...] Unha nova Morgana. Unha Morgana máis gris. Pero máis humana". (Caamaño, 2012:210). Por último, engendra un hijo incestuoso que a través de una visión percibe que es quien matará a Arturo. En él, pierde toda esperanza de un mundo mejor ya que se asemeja a las personas que representaron el dolor, la angustia, la ambición y la desolación (Viviana, Uther y Merlín).

"Todas elas paisaxes desoladas", la frase final de la obra explica claramente la máxima de la autora: todos contribuyeron, cada uno de diversa manera a este fatal destino: Merlín, Viviana, Ginebra, Arturo, Morgana. Son almas desoladas que llevan la carga de la culpa hasta el final de sus días.

\section{SORORIDAD}

La sororidad es un concepto que ha emergido en el comienzo de la lucha feminista en contraposición al patriarcado y al fraternalismo, sobre todo, a partir de la segunda mitad del siglo XX se ha convertido en el baluarte del movimiento feminista para exigir la igualdad de las mujeres en todos los ámbitos sociales. La primera vez que aparece el término fue en el diccionario Le Robert de la lengua francesa en el siglo XVI. Sigue el mismo modelo que fraternidad: "Amistad o afecto entre hermanos o entre quienes se tratan como tales", tomando el término latino "soror", que significa "hermana", "prima", "compañera" más el sufijo -dad, "cualidad de", esto es, "cualidad de hermana". Sorprende que en el diccionario de la RAE no aparezca registrada a pesar de que haya cobrado gran relevancia por señalar la lucha por la igualdad de derechos de la mujer y para desterrar los tópicos impuestos por una sociedad patriarcal como, por ejemplo, difamar que las mujeres debemos ser enemigas entre nosotras mismas. Sin embargo, en diversos diccionarios el mencionado Le Robert (sororité), en el inglés (sisterhood), en el italiano (sororitá) se encuentra la entrada de esta palabra aludiendo parte de la lucha que desde hace tiempo el feminismo lleva a cabo. Me parece muy acertada la reflexión de Cynthia sobre la sororidad en su blog Desde-ginebra "el idioma no es neutro, sino que es vehículo de valores, tradiciones y posiciones ideológicas. ¿Cómo explicar que "sonorité" y "sonority" sean términos de larga tradición en francés y en inglés, pero no en español'?" La sororidad pretende la unión de todas las mujeres para conseguir una vida distinta a la actual. No debe medirse el valor de una mujer según la posición social de su marido, padre o hijo. Otra lucha a la que se enfrenta es eliminar los estereotipos implantados desde hace tiempo: la dependencia emocional, está capacitada para cumplir sus propias ambiciones.

Los motivos por los que prevalecen estos convencionalismos contra las mujeres son diversos y, muchas veces, en conexión. Casi siempre la misoginia ocupa el lugar más

\footnotetext{
2 Desde-ginebra.blogspot.com.es/2014/03/sororidad.html.
} 
destacado que se embebe de las influencias del poder y de la religión concretamente. Si nos remitimos a los principios de los tiempos, la Diosa Madre / Tierra era venerada como la más grande y la principal entre todos los dioses. En este sentido, el Paleolítico nos muestra una mujer libre, respetada y consideraba como una diosa. Además, se creía que poseía el poder de elementos contrarios dado que representaban las distintas etapas de la Naturaleza: vida / muerte, blanco / negro, luz / oscuridad, etc. El negro simbolizaba la protección, la vida vinculada al útero de la mujer, al lugar donde se engendra una vida. Por otro lado, conocía las técnicas de la agricultura mediante la observación de las distintas fases de la luna, de los cambios experimentados por la misma naturaleza; los remedios naturales para la cura de algunas enfermedades. Posteriormente, el dualismo (bien /mal) de la Diosa Madre se decantará hacia el lado más oscuro, sobre todo, si incluimos la versión cristiana de las diosas antiguas y el destierro de la mujer a una simple posesión del hombre. El cristianismo ha alterado los ritos, los cultos paganos para amoldar e introducir a su Dios. Mientras que en el Dios cristiano se transformará en luz, en vida, en los poderes telúricos; en la diosa, este dualismo será la oscuridad y la muerte.

El poder y el dominio del hombre hacia la mujer se manifiesta en un tema recurrente en los textos antiguos y medievales es "la violación": Zeus viola a Calisto, perteneciente al clan de Artemisa; algunos caballeros de la Tabla Redonda también recurren a esta transgresión. Contrariadamente, no manifiestan dolor a causa de sus consecuencias, más bien, culpabilizan a la mujer de haber caído en sus redes y, quedaba señalada de por vida por la sociedad, por la familia ante el deshonor causado. En ocasiones, el hijo o la hija que nace de una violación, es una compensación por un acto heroico de un caballero a pesar de que en ciertos momentos de la historia se haya alejado de su viaje iniciático. Lancelot, en un principio, el caballero elegido para alcanzar el Santo Grial, es castigado por su relación adúltera con Ginebra. Dios no lo somete a una carga muy severa ya que decide concederle un hijo, que se convertirá en el mejor caballero y el que alcanzará el Santo Grial junto a Perceval y Boores.

Nuestro personaje Morgana reúne las características de la Diosa Artemisa ${ }^{3}$ un carácter indómito, protectora de las mujeres, curandera, castiga las malas acciones, va normalmente acompañada de ninfas o seres mágicos. Esta diosa representa el arquetipo de la hermana, esto es, lucha por la igualdad de ambos sexos, contra las injusticias y las agresiones sufridas por las mujeres como la agresión, el abuso de poder y de dominación y defiende la hermandad entre las mujeres. Geoffrey de Monmouth describía a Morgana como la mayor de nueve hermanas, la más bella y la más inteligente de todas, fuerte, inteligente, libre e independiente y protectora de las

3 Shinoda Bolen, Jean, Artemisa. El espiritu indómito de cada mujer, Barcelona, Kairós, 2015; Dunn Mascetti, Manuela, Diosas. La canción de Eva, Barcelona, Robinbook, S.L., 1992pp. 62-75. mujeres. Enseñaba a sus hermanas las artes, las matemáticas y el uso de las plantas para curar a los enfermos. La diosa "virgen" expresa no la ausencia de relaciones sexuales, sino la libertad de decisión de una mujer, la no pertenencia a otra persona y ser libre. Ambas no se muestran débiles ante nadie.

Mais l'acte de naissance de la fée Morgue est un passage de la Vie de Merlin (Vita Merlini) du même Geoffroy (1148), qui évoque l'île des Fruits, l'île Fortunée où règne la sage Morgue, aux pouvoirs de guérisseuse, l'ainée de neuf sœurs. C'est elle qui guérira le roi blessé pour lui permettre de revenir parmi le siens et de reconquérir la Bretagne. Elle a étudié les vertus médicinales de toutes les plantes reconquérir la Bretagne. Elle a étudié les vertus médicinales de toutes les plantes pour soulager les corps souffrants; on dit qu'elle a appris les mathématiques à ses
sœurs...

Es notorio el odio existente entre Ginebra y Morgana. El patriarcado explicó dicha enemistad para "demostrar" la ausencia de una buena relación entre las mujeres y mostrar la diferencia entre ambas según su educación moral. Ginebra fue educada en la religión católica, por tanto, al pecar por adulterio, será castigada mediante su reclusión en un monasterio. Morgana, sin embargo, poseía una actitud contraria a aquello que no comulgaba con los dogmas de fe. A partir del s. XIII, la Iglesia desechó todas sus características célticas, féericas, protectora de los caballeros. Al mismo tiempo, comenzó la batalla contra todo lo que significara la idea de una mujer independiente, sabia y libre expresada en las bulas papales, dictámenes de los padres y doctores de la Iglesia. Tomás de Aquino, veía a las mujeres sabias unas discípulas del demonio. Todas sus artes curativas, mágicas y de transformación eran transmitidas por el ser maligno.

En la Vulgata, Morgana es una amante despechada ya que Lancelot la rechaza porque solo está enamorado de Ginebra. Aquí comienza su enemistad, sumando que convenció a Guingamor, amante de Morgana a que la abandone. La versión de este personaje vivirá injustamente en los textos consecutivos, incluso en algunos de nuestra época. A pesar del intento de este sistema patriarcal, llama la atención que sea respetada y prevalezca el bagaje de su pasado céltico, no solo por ser la hermana del rey Arturo sino también por ser la discípula de Merlín, por sus conocimientos de magia, de encantamientos, por ser consejera de caballeros y de damas.

Pretendían acabar con cualquier signo femenino y con todo representante de la libertad de las mujeres. Gracias a la influencia de numerosas religiones separadas de la católica que pregonaban la igualdad, la libertad y el respeto, la continuidad de los cultos paganos no consiguieron derrocarlo en su totalidad. Si atendemos a los siguientes puntos, tal vez, nos puedan aclarar realmente quién era la hada y profetisa Morgana.

En cuanto a su hermandad, a su proteccionismo, ayudaba a las demás mujeres que habían sufrido un desencanto amoroso. Creó un lugar mágico, el Valle sin Retorno, apartado del mundo real, rodeado de magia donde las mujeres se sientes libres, sin 
ataduras, sin sumisión. Aquí el tiempo trascurre a otro ritmo. Se podría denominar, incluso, atemporal: no existe ni el pasado ni el futuro. La magia, las hadas, las ninfas, las druidas son los habitantes de este marco que no está sometido al paso del tiempo. Morgana quería demostrar lo que sospechaba desde siempre: "he hecho de ellos unos cobardes, unos viles, unos inconscientes" (Map, 1210:36); "sé por experiencia que el más bravo puede ser también el más cobarde". Reflejan unos pensamientos filosóficos que, junto a Merlín, albergaban un hondo pesar respecto al comportamiento humano, al destino del hombre, a su egocentrismo, a su conformismo. Asimismo, en diversos textos de la materia artúrica Morgana y sus ayudantas auxilian a los caballeros -que tenían un corazón puro- a conseguir sus propósitos y a casarse con su amada. En El Caballero del León ayuda al protagonista, Yvaín, a conseguir a su verdadero amor, la Dama de la Fuente. En la princesa lejana, aconseja a Guigemar cómo reparar el daño a una cierva que lo maldice en lo referente al amor.

El siguiente punto relevante se refiere al odio hacia su hermano Arturo, la causante de su destrucción. No es realmente cierto. Merlín había urdido desde el principio, el destino de los hombres y de las mujeres a su conveniencia, solamente para obtener su ambición. Entonces, ¿es posible considerar una reivindicación de la mujer el hecho de luchar por lo que era suyo antiguamente? Antes de la llegada del catolicismo, en los pueblos celtas, la línea sucesora correspondía a la madre, esto sería, de Igraine a Morgana. Incluso en nuestros antiguos pueblos prerromanos: los astures, las mujeres disponían de la autoridad para poseer tierras, tener trabajadores a su cargo e ir a la guerra con sus maridos. No obstante, esta ley cambió radicalmente bajo los designios de una sociedad patriarcal, imbuida de unos dogmas religiosos estrictos que despreciaron a las mujeres como un mero papel de cambio, de posesión o de instrumento. A partir del año 431 d.C., el cristianismo denominado "literalista" se rige por el Antiguo Testamento judío, patriarcal y monoteísta. Supone el fin de la igualdad de sexos y señalaba que los descendientes de la vil Eva a causa de su pecado, debían morir a través de su hijo y convirtió a las mujeres en seres humanos de segunda clase ${ }^{4}$.

Morgana siempre ha tenido la misma consideración de Ginebra: una relación entre iguales. Antes de conocerla, ya pensaba en ella como hermana por ser la esposa de su hermano y porque todas las mujeres debían tratarse con respeto. Cuando realiza el viaje iniciación o espiritual a Esmelle, va con la intención de solucionar el problema causado a Ginebra. Este viaje despierta el reconocimiento de una vida anterior basada en la egomanía y en satisfacer los egos individuales sin haber pensado en las consecuencias. Un camino de iniciación latente en la cultura celta, presente en los textos medievales efectuado por los caballeros de la Tabla Redonda o por aquel que perteneciera a

4 Frake, Timothy; Gandy, Peter, Jesús y la diosa perdida, Barcelona RBA integral, 2006, pp. 30-38; 60-80; 106142. este círculo. Es evidente entonces que no busca venganza ni reproche. En cambio, siente empatía hacia ella, le abre su corazón y le demuestra el sufrimiento que han padecido ambas por el hecho de seguir unas normas o cumplir unas expectativas como mujeres (esposa y hermana de un rey respectivamente): Ginebra, condicionada a ser la esposa perfecta, a renunciar a su libertad para satisfacer una norma social y religiosa arraigada, deja a un lado sus pretensiones en la vida, al hombre que realmente ama y le haría crecer interiormente. Morgana, a pesar de ser mayor que Arturo, queda retirada del poder. Su única salida para alcanzar la felicidad es vivir en la isla donde goza de auténtica libertad. Al final de la obra, plantea a su hermana Ginebra cómo ha sido la vida le explica por qué se siente así en esos momentos (ha vivido en un hogar y con unas normas patriarcales que le han convertido en un ser maltratado, castigado y lleno de culpas y de juicios) y por qué proyecta su odio y su ira hacia Morgana, hacia una igual que ha sufrido más o menos las mismas imposiciones en un mundo regido por la autoridad del hombre. El rencor, la ira, el odio se disipan gracias al entendimiento, al querer ver la realidad de su situación y, por lo tanto, el cambiarla. "Tan distintas, Xenebra e eu, e cantas semellanzas na nosa vida." (Caamaño, 2012:209)

\section{Conclusión}

Morgana no es el personaje tiránico, malvado y dispuesto a acabar con su hermano junto con su reino y su utopía. Al contrario, es una mujer que ayuda a su madre en primer lugar; después, a su tía Viviana y, finalmente, a su hermano Arturo. Nunca está ausente de los problemas que atañen a los personajes presentes en el texto. A través de diversas actitudes (sororidad) o simbolismos (la conciencia de Merlín), nuestra hada intenta conciliar a cada uno consigo mismo. No existen sentimientos negativos ni acciones de venganza ya que ha aprendido a encaminar lo que le hiere y lo que le provoca felicidad. Estas enseñanzas sobre la vida las transmite a los demás para que busquen su propio bienestar.

\section{REFERENCIAS Y BIBLIOGRAFÍA}

Alonso, María Lourdes, Las tres caras de Ginebra y Morgana. Psicología femenina en el mundo del Rey Arturo. Great Britain, Amazon, 2016.

Ávila Granados, J., La mitología celta. Madrid, Martínez Roca, 2007.

Caamaño, B., Morgana en Esmelle. Vigo, Galaxia (2012).

Clark, V., “La culpa diaria: negociando con el superyó”. Psicoanálisis XXIII, no 1 (2011), pp. 55-67.

Dunn Mascetti, M., Diosas. La canción de Eva, Barcelona, Robinbook, S.L., 1992. 
Elders, Leo, "El sentimiento de culpabilidad según la psicología, la literatura y la filosofía modernas". Reconciliación y Penitencia: V Simposio Internacional de la Teología de la Universidad de Navarra (1983), pp. 173-199.

Frake, T.- Gandy P., Jesús y la diosa perdida, Barcelona, RBA integra, 2006.

García-Haro, J., “Tres concepciones de la culpa: Historia y psicoterapia”. Revista electrónica de Psicoterapia, vol. 9 (2015), pp. 187-205.

Harf-Lancner, L., Le monde des fées dans l'occident médiéval, Paris, Hachette Littératures, 1991.

Largarde y de los Ríos, M., "Pacto entre mujeres sororidad". Aportes para el Debate. Internet. 20/03/17. <http://www.asociacionag.org.ar/pdfaportes/25/09.pdf

Markale, J., El ciclo de Grial. El hada Morgana. Barcelona, Martínez Roca S.A., 1997.

Markale, J., Pequeño diccionario de mitología céltica. Paris, Entente, 1991.

Mayorca, S., Los misterios de los Celtas. Barcelona, De Vecchi, 2009.

Mejía, María Paulina, “Culpa y deuda”. Affectio Societatis, no 6 (2002), pp. 1-7.

Ruiz Gómez, F., "La ilusión de la identidad en el imaginario medieval según Las Partidas". Revista Histórica, 9 (2008), pp. 239-261.

Shinoda Bolen, J., Artemisa. El espíritu indómito de cada mujer. Barcelona, Kairós, 2015.

Santelia, S., "Modelos femeninos en la antigüedad tardía", Cuadernos Medievales, 18 (2015), pp. 1-22.

Torres, A. T., "Sororidad", TFM-Marelis-Loreto. Internet. 21/03/17. <htpp://www. eprints.ucm.es/16835/1/TFM_Marelis_Loreto.pdf

Villegas M., Elkin E., “A qué llamamos cura del sentimiento de culpa?” Revista CES Psicología. Volumen 1, no 2 (2008), pp. 69-81.

Zorrilla Ortíz de Urbina, L., La figura de Morgana en la materia de bretaña hispánica. Victoria-Gasteiz, Las Modernas, 2015. 